J. Lake Sci. (湖泊科学), 2019, 31(4): 1023-1034

DOI 10. 18307/2019. 0422

(c) 2019 by Journal of Lake Sciences

\title{
城市湖泊春季绿藻水华特征及其影响因素——以宁波月湖为例”
}

\author{
周卢茜 ${ }^{1}$, 装钱玲琳 ${ }^{2,3}$, 唐剑锋 ${ }^{2,3}$, 徐耀阳 ${ }^{2,3}$, 潘军标 ${ }^{4}$, 王小德 ${ }^{1 * *}$ \\ ( 1 : 浙江农林大学风景园林与建筑学院, 杭州 311300$)$ \\ (2: 中国科学院城市环境研究所城市环境与健康重点实验室,厦门 361021) \\ (3: 中国科学院宁波城市环境观测研究站,宁波 315800$)$ \\ (4: 宁波天河水生态科技股份有限公司, 宁波 315012)
}

\begin{abstract}
摘 要: 城市湖泊富营养化问题日趋严峻, 以往对水华的研究多集中于大型自然淡水湖库, 而对小型城市浅水湖泊的水 华动态相对较少. 以宁波月湖为研究对象, 探讨水华暴发期间浮游植物变化特征及与影响因子之间的关系, 以期判别影 响城市湖泊水华的主控因子. 月湖水华期间营养盐水平处于中富营养至极端富营养之间, 此次共检出浮游植物 8 门 61 属, 藻种组成以绿藻门 $(51.79 \%)$ 和硅藻门 $(21.43 \%)$ 为主, 各点位浮游植物生长主要受水温、光照驱动, 经历了隐藻门 $\rightarrow$ 硅藻门 $\rightarrow$ 绿藻门 $\rightarrow$ 蓝藻门的演替. 水华种为雷氏衣藻 (Chlamydomonas reinhardtii), 总藻密度最高达到 $1.55 \times 10^{8} \mathrm{cells} / \mathrm{L}$, 水 华暴发后各点位衣藻属比例升高(最高达到 81.10\%), 群落结构呈现单一化特征. 通过 Pearson 相关性分析和 RDA 分析发 现衣藻属生长与水温、 $\mathrm{pH}$ 、总磷浓度均呈显著正相关, 春季气温回升、天气持续晴好, 城市浅水湖泊高营养盐负荷、水体流 动性差等特点为带鞭毛的衣藻属提供了适宜的生存条件, 在环境条件均适宜的情况下拥有最大生长潜力的衣藻属在营 养盐、光照等竞争中生长速率明显优于其他藻种,从而发生绿藻水华.
\end{abstract}

关键词: 浮游植物; 城市湖泊;月湖; 绿藻水华; 影响因子

\section{Characteristics of spring green algae blooms and their influencing factors in an urban lake, Moon Lake in Ningbo City, China}

\author{
ZHOU Luxi ${ }^{1}$, QIU Qianlinglin ${ }^{2,3}$, TANG Jianfeng ${ }^{2,3}$, XU Yaoyang $^{2,3}$, PAN Junbiao $^{4} \&$ WANG Xiaode ${ }^{1 * *}$ \\ (1: School of Landscape Achitecture, Zhejiang Agricultural and Forestry University, Hangzhou 311300, P.R.China) \\ (2: Key Laboratory of Urban Environment and Health, Institute of Urban Environment, Chinese Academy of Sciences, Xiamen \\ 361021, P.R.China) \\ (3: Ningbo Urban Environment Observation and Research Station, Chinese Academy of Sciences, Ningbo 315800, P.R. China) \\ (4: Ningbo Tianhe Aquatic Ecosystems Engineering Co. Ltd, Ningbo 315012, P.R.China)
}

Abstract: Eutrophication of urban lakes is a growing threat. Previous studies on algal blooms have focused on large natural freshwater reservoirs, but the dynamics of algal blooms in small urban shallow lakes are largely unknown. To identify the key factors affecting algal blooms in urban lakes, this paper analyzed the characteristics of phytoplankton variation and the relationship between phytoplankton and contributing factors in a typical urban lake, Moon Lake in Ningbo, China. During the bloom, the nutrient level of Moon Lake was between moderately eutrophication and extreme eutrophication. A total of 61 genera of phytoplankton belonging to 8 phyla were found and were dominated by Chlorophyta $(51.79 \%)$ and Bacillariophyta $(21.43 \%)$. The results showed that water temperature and light were found to be the main factors for phytoplankton growth, which was characterized by a succession of Cryptophyta, Bacillariophyta, Chlorophyta and Cyanophyta. Chlamydomonas reinhardtii caused the bloom and had a population density as high as $1.55 \times 10^{8}$ cells/L. As algae density increased, the proportion of Chlamydomonas spp. increased ( reached $81.10 \%$ ), while the species numbers and community stability of the phytoplankton decreased. The subsequent Pearson correlation analysis and redundancy analysis also demonstrated that the growth of Chlamydomonas was positively correlated with water temperature, $\mathrm{pH}$ and

* 国家重点研发计划项目 (2017YFE0119000) 和中国科学院城市环境与健康重点实验室项目 (KLUEH-C-201701) 联 合资助. 2018-12-12 收稿;2019-01-25 收修改稿. 周卢茜(1994 ), 女, 硕士研究生;E-mail:651217465@ qq.com.

** 通信作者; E-mail:wxd65@ zafu.edu.cn. 
total phosphorus. Rising temperature in the spring season, continuous sunny weather, high nutrient loads in urban shallow lakes and poor fluidity of water body helped create suitable living conditions for Chlamydomonas spp. with flagellum. Under these circumstances, the Chlamydomonas spp. with the greatest growth potential outnumbered other algae species in the competition of nutrients, light and other resources, resulting in the green algae blooms.

Keywords: Phytoplankton; urban lake; Moon Lake; green algae bloom; influencing factors

近年来随着我国城市化的高速发展, 剧烈的人类活动产生的大量氮、磷营养盐进人城市湖泊, 加速了水 体富营养化进程、引发水华现象. 作为湖泊富营养化的典型特征, 水华事件的发生使得水体透明度降低、溶 解氧浓度下降、鱼类及其他生物大量死亡, 最终导致水体自净能力失衡 ${ }^{[1-2]}$, 严重威胁城市水生态系统. 目前 城市湖泊的水质不容乐观, $\mathrm{Lv}$ 等 ${ }^{[3]}$ 对武汉 15 个城市浅水湖泊调查显示, 湖泊的总磷浓度平均达到 $0.49 \mathrm{mg} / \mathrm{L}$, 且以南太子湖的氮磷营养富集最高. 其他城市景观湖泊如芜湖镜湖、汀棠湖处于轻度富营养 化 ${ }^{[4]}$, 南昌青山湖处于轻一中度富营养化 ${ }^{[5]}$, 西湖、大明湖等水质均为 $\mathrm{V}$ 类或劣 $\mathrm{V}$ 类 ${ }^{[6]}$ 、富营养化严重, 南京 玄武湖、广州流花湖、昆明翠湖曾暴发蓝藻水华 ${ }^{[7]}$.

据陈能汪等 ${ }^{87}$ 统计, 我国淡水水华发生时间集中于 3-9 月, 常见水华藻中蓝藻占 $81 \%$, 甲藻、绿藻、硅 藻各占 $6 \%$. 大量研究表明,水华的形成与发展是生态系统内藻类与多种环境因素作用的结果 ${ }^{[9-10]}$. 浮游植 物是湖泊生态系统的初级生产者、水体营养等级的重要指示生物 ${ }^{[11]}$, 其数量变化、群落结构、优势种演替均 与环境因子密切相关, 并引发水环境条件的变化、进一步影响水域生态系统的结构与功能 ${ }^{[12-13]}$. 不同藻类对 环境的适应性有差异, 如硅藻、甲藻属于狭冷型藻, 易于在春季暴发水华 ${ }^{[14]}$, 绿藻、蓝藻的适温较高, 易于在 夏季占据主导地位 ${ }^{[15]}$; 高氮磷水体中绿藻比蓝藻有更强的利用优势, 蓝藻在很多处于超富营养化状态水体 中不占优势 ${ }^{[16-17]}$. 除水温、营养盐水平外, 流速、水位、光照等气象水文条件亦能影响各类水华的严重 程度 ${ }^{[18-19]}$.

然而现阶段研究多在探讨我国大型淡水湖库中浮游植物群落结构与水环境条件的关系 ${ }^{[7,16,19-20]}$, 对城 市湖泊的相关研究较为少见. 城市湖泊相较于作为水源地的大型湖泊和河流库区, 由于所处地理位置、功能 定位不同, 所受人类活动的影响更大, 水体环境条件、藻种组成及水华暴发特征均有其特殊性. 月湖作为宁 波城市中心的浅水湖泊, 具备洪涝调蓄的生态功能,作为人文地标又承担了旅游休闲、景观娱乐的社会功 能, 对城市发展起到重要作用. 但近年来水华频发、局部出现季节性黑臭, 水质有逐渐恶化的趋势, 大大削减 了其作为城市湖泊所产生的生态与社会效益. 本研究以月湖为例, 结合水体理化参数对各点位进行营养水 平分级, 在此基础上分析水华期间浮游植物分布与变化特征, 从中构建浮游植物分布与环境因子之间的联 系,探讨水华暴发原因及影响因子,为城市湖泊环境监测、水华治理提供思路.

\section{1 材料与方法}

\section{1 研究区域概况}

月湖 $\left(29^{\circ} 51^{\prime} 56^{\prime \prime} \sim 29^{\circ} 52^{\prime} 27^{\prime \prime} \mathrm{N}, 121^{\circ} 32^{\prime} 8.62^{\prime \prime} \sim 121^{\circ} 32^{\prime} 25.18^{\prime \prime} \mathrm{E}\right.$ ) 位于宁波市海曙区, 地处亚热带季风气候 区, 年平均气温 $16.4^{\circ} \mathrm{C}, 7$ 月平均温度 $28.0^{\circ} \mathrm{C}, 1$ 月平均温度 $4.7^{\circ} \mathrm{C}$, 年均降水量 $1480 \mathrm{~mm}$. 月湖总水域面积为 $9 \mathrm{hm}^{2}$, 库容量约为 $4 \times 10^{5} \mathrm{~m}^{3}$. 月湖北侧的建筑群密集, 与营养盐负荷较高的护城河相连; 南侧建筑群稀疏, 人流密集程度相对北侧减少. 污染源有随水流方向自北向南、自西向东流动的趋势. 综合考虑污染源分布和 水动力学特性, 兼顾船行便捷和长期监测的需求, 共布设 6 个采样点 (图 1). S1 为出水口, $\mathrm{S} 4$ 为人水口、与 护城河相连. 其余 4 个点位位于主景区:S2 靠近游船码头, S3 位于休媳亭边, S5、S6 位于密集建筑群旁. 其中 S1 S4 位于水面开阔处,水体交换条件良好;S5、S6 位于水面狭窄、水湾处,水体交换条件相对欠缺.

\section{2 样品采集与处理}

2018 年 3 月 12 日 -5 月 3 日 ( 8 周) 按周在月湖各个采样点进行水样与浮游植物样品采集. 现场记录采 样时间、天气, 结合拍照记录水色; 用采水器采集水下 $0.5 \mathrm{~m}$ 处水样 $5 \mathrm{~L}, 2.5 \mathrm{~L}$ 用于水质参数测定, $2.5 \mathrm{~L}$ 加人 $20 \mathrm{ml}$ 鲁哥氏剂固定, 用于浮游植物的鉴定计数; 采用多参数数字化分析仪 (美国哈希, HQ40D) 测定水温 (WT)、 $\mathrm{pH}$ 、盐度和溶解氧浓度, 用萨氏盘测定水体透明度 $(\mathrm{SD})$.

水质参数参照《地表水环境质量标准》(GB 3838-2002) 进行测定: 利用哈希 DR6000 分光光度计测定 


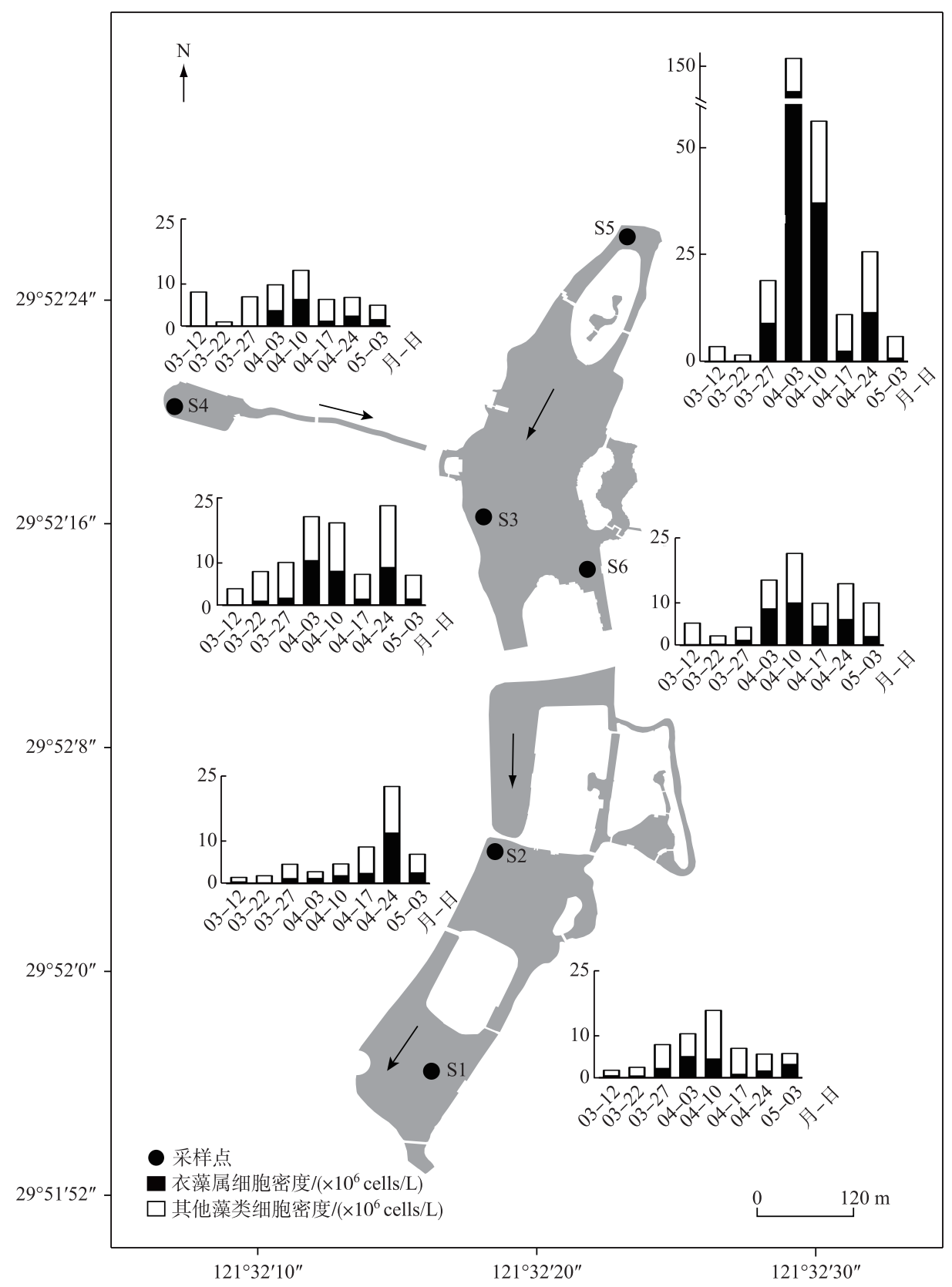

图 1 月湖采样点分布与藻类细胞密度时空变化

Fig.1 Distribution of sampling sites and temporal and spatial variation of algae density in Moon Lake

总悬浮物 (TSS) 、化学需氧量 (COD), 采用碱性过硫酸钾消解紫外分光光度法测定总氮 (TN) 浓度, 采用钼酸 铵分光光度法测定总磷 (TP) 浓度, 采用离子色谱法 (赛默飞, ICS-5000) 测定 $\mathrm{NO}_{2}^{-} 、 \mathrm{NO}_{3}^{-}$等阴离子浓度,采用 流动分析仪 (德国 Seal, AA3) 测定铵态氮 $\left(\mathrm{NH}_{4}^{+}-\mathrm{N}\right)$ 浓度, 采用热乙醇萃取法测定叶绿素 $\mathrm{a}(\mathrm{Chl} . \mathrm{a})$ 浓度 ${ }^{[21]}$.

浮游植物样品采集参照《内陆水域浮游植物监测技术规程》(SL 733-2016), 水样经 $48 \mathrm{~h}$ 静置沉淀并经 虹吸法浓缩后, 于 $10 \times 40$ 倍光学显微镜 (尼康 Ti-U 苂光倒置显微镜) 下观察, 参照《中国淡水藻类——系统、 
分类及生态》和相关图谱 ${ }^{[22-24]}$ 进行浮游植物种类鉴定, 并完成计数工作.

\section{3 数据分析}

1.3.1 富营养化程度评价 考虑到月湖尚未形成稳定的沉水植物群落, 春季水华暴发期间湖泊状态以藻型为 主, 叶绿素 a 作为能够综合反映湖泊藻类数量多塞的指标, 常作为此类湖泊的主要评价因子 ${ }^{[25]}$. 采用国际公 认的叶绿素 a 浓度分级法能够独立对湖泊营养状态进行分级, 从而进一步分析水华暴发的环境条件. 该法 按照叶绿素a 浓度水平将湖泊营养物控制标准分为 6 级: I 级贫营养 $\left(<1.6 \mathrm{mg} / \mathrm{m}^{3}\right) 、$ II 级中营养 $(1.61 \sim 10$ $\left.\mathrm{mg} / \mathrm{m}^{3}\right)$ 、III 级轻富营养 $\left(10 \sim 26 \mathrm{mg} / \mathrm{m}^{3}\right) 、 I V$ 级中富营养 $\left(26 \sim 64 \mathrm{mg} / \mathrm{m}^{3}\right) 、 V$ 级重富营养 $\left(64 \sim 160 \mathrm{mg} / \mathrm{m}^{3}\right) 、 V I$ 级极端富营养 $\left(>160 \mathrm{mg} / \mathrm{m}^{3}\right)^{[25-26]}$.

1.3.2 群落特征指数分析 运用 Shannon-Wiener 多样性指数 $\left(H^{\prime}\right) 、$ Pielou 均匀度指数 $(J) 、$ Margalef 丰富度指 数 $(R)$ 描述浮游植物群落特征, 公式如下 ${ }^{[20,27]}$ :

$$
\begin{gathered}
H^{\prime}=-\sum\left(n_{i} / N\right) \ln \left(n_{i} / N\right) \\
J=H^{\prime} / \ln S \\
R=(S-1) / \ln N \\
Y=n_{i} / N \cdot f_{i}
\end{gathered}
$$

式中, $n_{i}$ 为第 $i$ 种藻类的个数, $N$ 为所有藻类的总个数, $S$ 为样品中藻类种类数, $f_{i}$ 为第 $i$ 种藻类在各点位出现 的频率. 本文将优势度 $Y>0.02$ 的藻类定为优势种.

分别采用 SPSS 22.0 软件进行 Pearson 相关系数计算, Canoco 5.0 进行先余分析 (RDA) 以进一步探讨环 境因子对月湖浮游植物分布的影响 ${ }^{[28]}$.

\section{2 结果与分析}

\section{1 水质参数与富营养化分级}

月湖各样点在水华前后的水温变化范围为 $11.69 \sim 23.35^{\circ} \mathrm{C} 、 \mathrm{pH}$ 为 7.47 9.72、 $\mathrm{DO}$ 浓度为 $0 \sim 23.14 \mathrm{mg} / \mathrm{L}$ 、 $\mathrm{SD}$ 为 $0.4 \sim 1.5 \mathrm{~m}$ 、TSS 为 $4.67 \sim 62.33 \mathrm{mg} / \mathrm{L} 、 \mathrm{COD}$ 为 $12.47 \sim 51.80 \mathrm{mg} / \mathrm{L} 、 \mathrm{TN}$ 浓度为 $0.19 \sim 25.94 \mathrm{mg} / \mathrm{L} 、 \mathrm{TP}$ 浓度 为 $0.02 \sim 0.69 \mathrm{mg} / \mathrm{L} 、 \mathrm{NH}_{4}^{+}-\mathrm{N}$ 浓度为 $0.01 \sim 2.59 \mathrm{mg} / \mathrm{L} 、 \mathrm{Chl}$. a 浓度为 $9.82 \sim 869.92 \mathrm{mg} / \mathrm{m}^{3}$. 月湖水质总体偏弱碱 性、营养盐浓度较高, 各项水质指标介于 II 类至劣 $\mathrm{V}$ 类. 其中 $\mathrm{S} 1 、 \mathrm{~S} 2$ 处于 II $\sim$ III 类, S3、S6 处于 IV V 类, S4、

\begin{tabular}{|c|c|c|c|c|c|c|c|c|c|c|c|c|}
\hline 点位 & $\begin{array}{c}\mathrm{SD} / \\
\mathrm{m}\end{array}$ & $\begin{array}{l}\text { WT/ } \\
{ }^{\circ} \mathrm{C}\end{array}$ & $\mathrm{pH}$ & $\begin{array}{c}\mathrm{D} 0 / \\
(\mathrm{mg} / \mathrm{L})\end{array}$ & $\begin{array}{c}\text { TSS/ } \\
(\mathrm{mg} / \mathrm{L})\end{array}$ & $\begin{array}{c}\mathrm{COD} / \\
(\mathrm{mg} / \mathrm{L})\end{array}$ & $\begin{array}{c}\mathrm{TN} / \\
(\mathrm{mg} / \mathrm{L})\end{array}$ & $\begin{array}{c}\mathrm{TP} / \\
(\mathrm{mg} / \mathrm{L})\end{array}$ & $\begin{array}{l}\mathrm{NO}_{2}^{-}-\mathrm{N} / \\
(\mathrm{mg} / \mathrm{L})\end{array}$ & $\begin{array}{l}\mathrm{NO}_{3}^{-}-\mathrm{N} / \\
(\mathrm{mg} / \mathrm{L})\end{array}$ & $\begin{array}{l}\mathrm{NH}_{4}^{+}-\mathrm{N} / \\
(\mathrm{mg} / \mathrm{L})\end{array}$ & $\begin{array}{l}\text { Chl.a/ } \\
\left(\mathrm{mg} / \mathrm{m}^{3}\right)\end{array}$ \\
\hline S1 & $0.93 \pm 0.26$ & $18.46 \pm 3.98$ & $8.62 \pm 0.41$ & $11.44 \pm 2.50$ & $13.29 \pm 5.00$ & $18.40 \pm 3.91$ & $0.91 \pm 0.32$ & $0.08 \pm 0.03$ & $0.04 \pm 0.01$ & $0.29 \pm 0.11$ & $0.06 \pm 0.06$ & $69.03 \pm 37.43$ \\
\hline S2 & $1.14 \pm 0.25$ & $18.58 \pm 4.01$ & $8.71 \pm 0.35$ & $10.51 \pm 2.34$ & $11.33 \pm 4.36$ & $17.28 \pm 4.37$ & $3.13 \pm 5.98$ & $0.08 \pm 0.05$ & $0.04 \pm 0.01$ & $0.33 \pm 0.11$ & $0.08 \pm 0.11$ & $32.50 \pm 8.62$ \\
\hline S3 & $0.88 \pm 0.26$ & $18.62 \pm 4.12$ & $8.90 \pm 0.56$ & $12.17 \pm 3.01$ & $15.00 \pm 5.01$ & $24.68 \pm 4.96$ & $2.01 \pm 0.40$ & $0.14 \pm 0.08$ & $0.07 \pm 0.01$ & $0.78 \pm 0.27$ & $0.13 \pm 0.11$ & $116.62 \pm 48.66$ \\
\hline S4 & $0.71 \pm 0.14$ & $18.31 \pm 3.65$ & $8.09 \pm 0.71$ & $6.28 \pm 5.16$ & $18.42 \pm 7.03$ & $27.49 \pm 6.09$ & $5.64 \pm 3.25$ & $0.38 \pm 0.20$ & $0.18 \pm 0.06$ & $0.63 \pm 0.33$ & $1.61 \pm 0.70$ & $108.31 \pm 89.17$ \\
\hline S5 & $0.61 \pm 0.18$ & $18.57 \pm 3.71$ & $8.62 \pm 0.82$ & $11.19 \pm 6.91$ & $26.50 \pm 16.62$ & $32.94 \pm 11.61$ & $6.07 \pm 7.62$ & $0.27 \pm 0.18$ & $0.08 \pm 0.02$ & $0.62 \pm 0.31$ & $0.36 \pm 0.32$ & $270.44 \pm 280.94$ \\
\hline S6 & $0.82 \pm 0.33$ & $18.49 \pm 3.69$ & $9.08 \pm 0.45$ & $12.38 \pm 4.23$ & $18.83 \pm 8.05$ & $26.42 \pm 8.23$ & $2.35 \pm 0.67$ & $0.15 \pm 0.09$ & $0.06 \pm 0.01$ & $0.76 \pm 0.25$ & $0.11 \pm 0.11$ & $146.88 \pm 100.89$ \\
\hline
\end{tabular}
S5 多处于劣 $\mathrm{V}$ 类( 《地表水环境质量标准》 (GB 3838-2002)), 各样点的水质理化参数情况见表 1 .

表 1 月湖各点位水质理化参数*

Tab.1 Physical and chemical water parameters of each sampling site in Moon Lake

*每个点位的样本数 $n=8$.

以叶绿素 a 浓度分级法对月湖水体营养水平进行分级, 结果表明, 月湖在采样期间营养水平处于中富 营养至极端富营养之间, 其中处于重富营养水平的样点占比最大 $(35.42 \%)$; 就各样点样本数量分布来看, 其 营养水平从高到低依次为: $\mathrm{S} 5>\mathrm{S} 6>\mathrm{S} 3>\mathrm{S} 4>\mathrm{S} 1>\mathrm{S} 2$ (表 2), 其中 $\mathrm{S} 5$ 的水温、TP、TN、氮磷比等水质参数随时间 变化情况见图 2. 
表 2 基于叶绿素 a 浓度的各点位营养水平分级

Tab.2 Physical and chemical parameters of each sampling site based on chlorophyll-a concentration

\begin{tabular}{|c|c|c|c|c|c|c|c|c|}
\hline \multirow{2}{*}{ 营养分级 } & \multicolumn{6}{|c|}{ 各样点样本数量 } & \multirow{2}{*}{ 合计 } & \multirow{2}{*}{$\begin{array}{c}\text { 百分比 } \\
\%\end{array}$} \\
\hline & S1 & S2 & $\mathrm{S} 3$ & $\mathrm{~S} 4$ & S5 & S6 & & \\
\hline 贫营养( <1.6 mg/m³) & 0 & 0 & 0 & 0 & 0 & 0 & 0 & 0 \\
\hline 中营养 (1.6 10 mg/m³) & 0 & 0 & 0 & 1 & 0 & 0 & 1 & 2.08 \\
\hline 轻富营养 ( $10 \sim 26 \mathrm{mg} / \mathrm{m}^{3}$ ) & 2 & 1 & 0 & 0 & 1 & 1 & 5 & 10.42 \\
\hline 中富营养( 26 64 mg/m³) & 1 & 7 & 2 & 2 & 1 & 1 & 14 & 29.17 \\
\hline 重富营养 (64 160 mg/m³) & 5 & 0 & 4 & 3 & 2 & 3 & 17 & 35.42 \\
\hline 极端富营养 (>160 mg/m³) & 0 & 0 & 2 & 2 & 4 & 3 & 11 & 22.92 \\
\hline
\end{tabular}
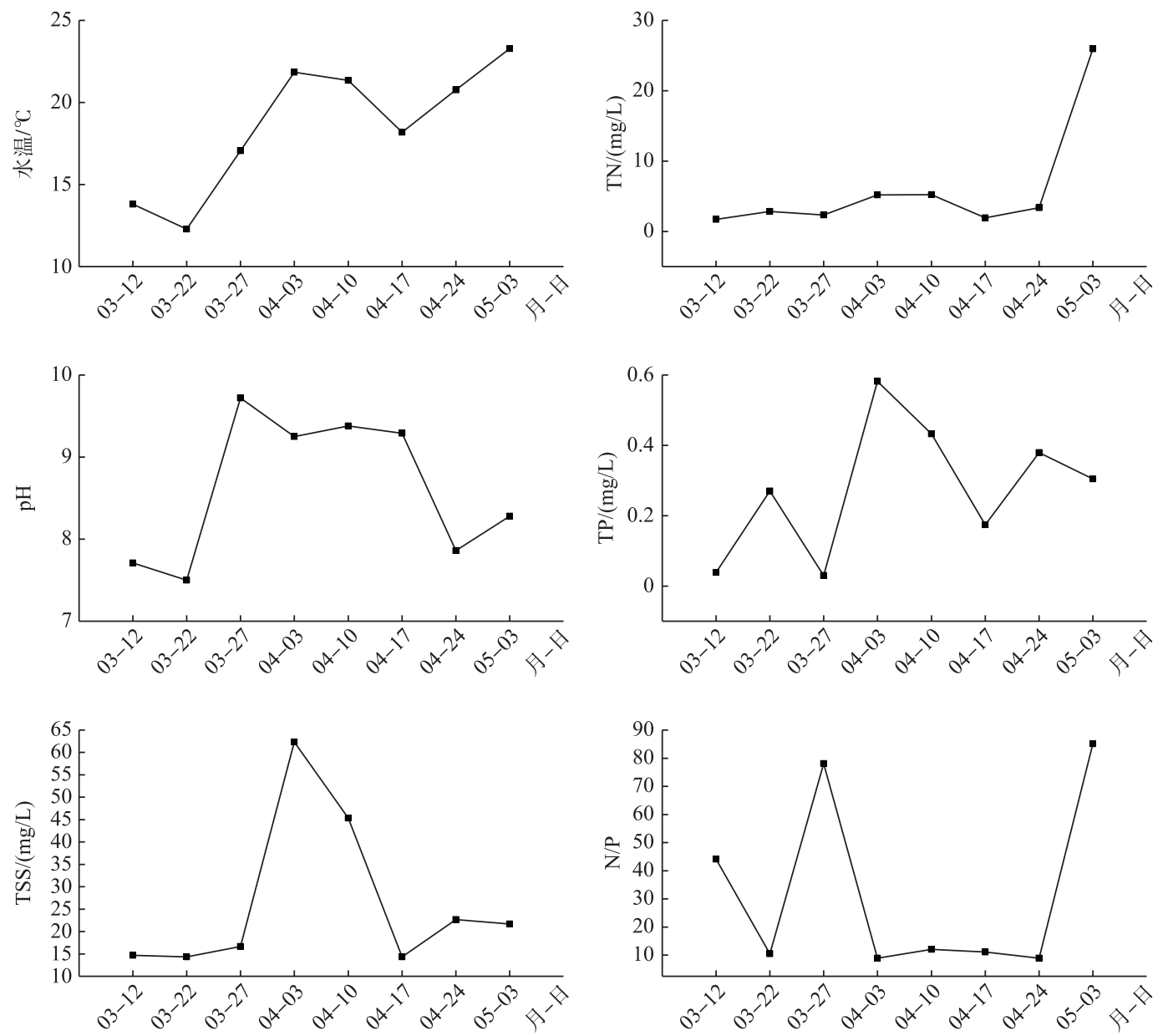

图 $2 \mathrm{~S} 5$ 点位部分水质参数随时间变化

Fig.2 Temporal variation of partial water quality parameters of site S5

\section{2 浮游植物群落特征分析}

2.2 .1 浮游植物群落结构基本分析 在月湖各点位共发现浮游植物 112 种 (含变种), 隶属于 8 门 34 科 61 属. 种类组成按比重由高到低依次为绿藻门 ( 58 种, 51.79\%)、硅藻门 ( 24 种, 21.43\%)、裸藻门 ( 13 种, $11.61 \%$ )、蓝藻门(10 种, $8.93 \%$ )、隐藻门(3 种, 2.68\%)、甲藻门( 2 种, $1.79 \%$ ), 金藻门和黄藻门均为 1 种、 
占比 $0.89 \%$, 其中绿藻门在丰度上亦占据绝对优势, 约占总藻密度的 $67.24 \%$. 其次为硅藻门 $(14.15 \%)$ 、隐藻 门 $(12.51 \%)$ 、蓝藻门 $(5.24 \%)$, 其余 4 门合计占总藻密度的 $0.87 \%$.

月湖浮游植物的优势属 $(Y>0.02)$ 有浮鞘丝藻属 (Planktolyngbya) 、小尖头藻属 (Raphidiopsis)、小环藻属 (Cyclotella)、脆杆藻属 (Fragilaria)、针杆藻属 (Synedra)、隐藻属 (Cryptomona)、蓝隐藻属 (Chroomonas)、薄甲 藻属 (Glenodinium) 、囊裸藻属 (Trachelomonas) 、衣藻属 (Chlamydomonas)、四鞭藻属 (Carteria) 、小球藻属 (Chlorella)、四角藻属 (Tetraëdron)、纤维藻属 (Ankistrodesmus)、栅藻属 (Scenedesmus) 共 15 属. 从表 3 第一优 势属的变化上看, 月湖各点位浮游植物大体经历了隐藻门 $\rightarrow$ 硅藻门 $\rightarrow$ 绿藻门 $\rightarrow$ 蓝藻门的演替, 且 4 月 3 日一 4 月 24 日衣藻属始终为第一优势属.

\section{表 3 月湖浮游植物优势属、门类时间演替}

Tab.3 Temporal succession of dominant genera and phyla of phytoplankton in Moon Lake

\begin{tabular}{cll}
\hline 时间 & 主要优势属与优势度 & 所属门 \\
\hline 3 月 12 日 & 隐藻属 $(0.63)$ & 隐藻门 \\
3 月 22 日 & 小环藻属 $(0.29) 、$ 隐藻属 $(0.17)$ 、蓝隐藻属 $(0.11)$ & 硅藻门、隐藻门 \\
3 月 27 日 & 小环藻属 $(0.41) 、$ 衣藻属 $(0.29)$ & 硅藻门、绿藻门 \\
4 月 3 日 & 衣藻属 $(0.72)$ & 绿藻门 \\
4 月 10 日 & 衣藻属 $(0.52) 、$ 四鞭藻属 $(0.16)$ & 绿藻门 \\
4 月 17 日 & 衣藻属 $(0.26) 、$ 四鞭藻属 $(0.22) 、$ 小环藻属 $(0.19)$ & 绿藻门、硅藻门 \\
4 月 24 日 & 衣藻属 $(0.43) 、$ 四鞭藻属 $(0.14) 、$ 小环藻属 $(0.11)$ & 绿藻门、硅藻门 \\
5 月 3 日 & 浮鞘丝藻属 $(0.32) 、$ 衣藻属 $(0.29)$ & 蓝藻门、绿藻门 \\
\hline
\end{tabular}

2.2.2 各点位水华程度比较 S5 (临近北人水口) 于 3 月 28 日暴发绿藻水华, 持续时间约 4 周, 藻密度达到 $1.55 \times 10^{8} \mathrm{cells} / \mathrm{L}$, 期间湖面水色呈鲜绿色且伴有绿色浮膜. 经镜检以雷氏衣藻 (Chlamydomonas reinhardtii) 为 代表的衣藻属占据绝对优势 ( $81.10 \%)$. 图 1 为衣藻属和总藻密度的时空变化, 各点位总藻密度随衣藻属密 度从 3 月 27 日起明显上升, 先后于 4 月 3 日、10 日达到最大值, 此时各点位衣藻属在总藻密度中的占比在 $43 \%$ 以上. 之后衣藻属密度逐渐下降, 尽管在 4 月 24 日有所回升但基本得到控制.

衣藻属作为水华属, 其数量变化可大致反映水华程度. 水华期间位于北湖的 S5、S3、S6 衣藻属密度上升 幅度最大, 分别为 $8.94 \times 10^{6} 、 8.71 \times 10^{6}$ 和 $7.29 \times 10^{6} \mathrm{cells} / \mathrm{L} ; \mathrm{S} 5 、 \mathrm{~S} 4 、 \mathrm{~S} 3$ 衣藻属占比上升幅度最大, 分别为 $46.6 \% 、 36.8 \%$ 和 $33.6 \%$, 但 S4 的总藻密度并未有大幅变化. 位于南湖的 S1、S2 在藻密度、衣藻属占比上变化 相对较小, 由此各点水华程度从高到低依次为: $\mathrm{S} 5>\mathrm{S} 3>\mathrm{S} 6>\mathrm{S} 4>\mathrm{S} 1>\mathrm{S} 2$, 与营养水平排序基本对应. 通过表 4 可知, 北湖 S6、S3 的群落特征指数普遍小于南湖 $\mathrm{S} 1 、 \mathrm{~S} 2, H^{\prime} 、 J 、 R$ 的最低值也同时出现在 4 月 3 日的 $\mathrm{S} 5$ (2.676、0.796 和 0.258$)$, 水华暴发导致衣藻属占绝对优势、浮游植物群落结构单一化.

表 4 各点位浮游植物群落特征指数*

Tab.4 Phytoplankton community characteristic index of each sampling site

\begin{tabular}{ccccccc}
\hline 群落特征指数 & $\mathrm{S} 1$ & $\mathrm{~S} 2$ & $\mathrm{~S} 3$ & $\mathrm{~S} 4$ & $\mathrm{~S} 5$ & $\mathrm{~S} 6$ \\
\hline$H^{\prime}$ & $1.860 \pm 0.138$ & $1.945 \pm 0.163$ & $1.782 \pm 0.165$ & $1.957 \pm 0.446$ & $1.619 \pm 0.397$ & $1.696 \pm 0.316$ \\
$J$ & $0.586 \pm 0.047$ & $0.616 \pm 0.057$ & $0.563 \pm 0.061$ & $0.595 \pm 0.137$ & $0.523 \pm 0.121$ & $0.528 \pm 0.085$ \\
$R$ & $3.406 \pm 0.388$ & $3.556 \pm 0.669$ & $3.365 \pm 0.200$ & $3.894 \pm 0.379$ & $3.132 \pm 0.504$ & $3.374 \pm 0.527$ \\
\hline
\end{tabular}

$*$ 每个点位的样本数 $n=8$.

2.2.3 特征点位浮游植物组成变化 S5 作为水华暴发点, 其浮游植物第一优势属密度在总藻密度中的占比 随时间变化的情况见图 3. 结果显示, S5 浮游植物先后由隐藻属、小环藻属、衣藻属、浮鞘丝藻属占优势, 其 组成变化与全湖浮游植物发生的演替一致. 隐藻属占比在第 1 周达到最大值, 后急剧下降呈小幅上下波动; 与之对应的浮鞘丝藻属前期密度波动范围不大, 在第 8 周急剧上升达到最大值. 小环藻属起初密度上升, 水 华暴发后随着衣藻属密度上升而下降, 水华得到控制后随衣藻密度下降而上升, 在第 8 周二者密度同时 
回落.

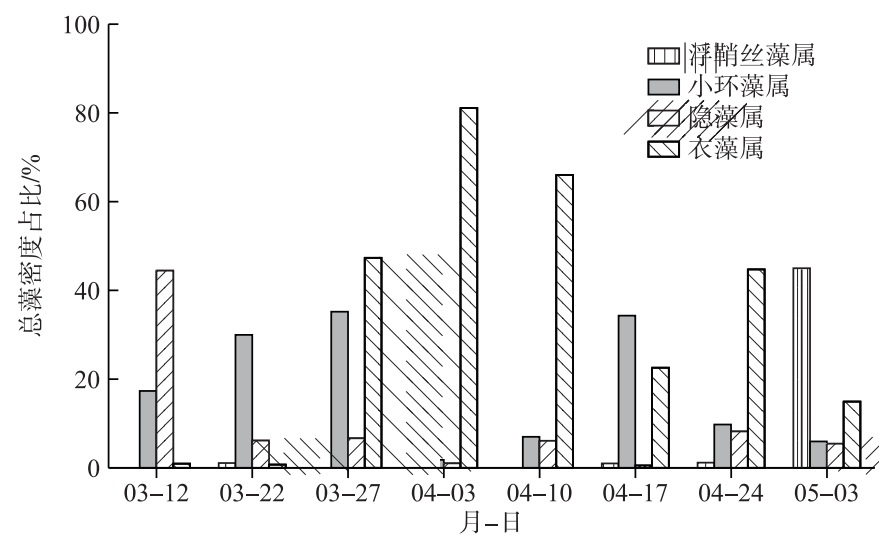

图 $3 \mathrm{~S} 5$ 浮游植物特征属占比随时间变化

Fig.3 Time variation of phytoplankton characteristic genus density proportion of S5

\section{3 浮游植物与环境因子关系分析}

环境因子对浮游植物的影响主要体现在密度和分布上. Pearson 相关性分析表明, 月湖藻密度和群落特 征指数与 WT、TN、N/P、 $\mathrm{NO}_{3}^{-}-\mathrm{N}$ 和 $\mathrm{NH}_{4}^{+}-\mathrm{N}$ 均无显著相关关系. 其中藻密度与 TSS、COD、TP 和 Chl. a 均呈显著 正相关, 与 $\mathrm{SD}$ 呈显著负相关; 群落特征指数均与 $\mathrm{NO}_{2}^{-}-\mathrm{N}$ 呈显著正相关, 与 $\mathrm{pH} 、 \mathrm{DO} 、 \mathrm{TSS} 、 \mathrm{Chl}$. a 均呈显著负相 关, 其中多样性指数 $H^{\prime}$ 、丰富度指数 $J$ 与 COD 均呈显著负相关, 而均匀度指数 $R$ 与 COD 无显著相关关系 (表 5).

表 5 月湖环境因子与藻密度、群落特征指数相关性分析

Tab.5 The correlation of algae density and community characteristic index with environmental factors in Moon Lake

\begin{tabular}{ccccccccc}
\hline & $\mathrm{SD}$ & $\mathrm{pH}$ & $\mathrm{DO}$ & $\mathrm{TSS}$ & $\mathrm{COD}$ & $\mathrm{TP}$ & $\mathrm{NO}_{2}^{-}-\mathrm{N}$ & $\mathrm{Chl} . \mathrm{a}$ \\
\hline 藻密度 & $-0.396^{* *}$ & 0.273 & 0.113 & $0.802^{* *}$ & $0.620^{* *}$ & $0.435^{* *}$ & -0.113 & $0.882^{* *}$ \\
$H^{\prime}$ & 0.206 & $-0.419^{* *}$ & $-0.546^{* *}$ & $-0.456^{* *}$ & $-0.403^{* *}$ & -0.024 & $0.386^{* *}$ & $-0.543^{* *}$ \\
$J$ & 0.239 & $-0.292^{*}$ & $-0.305^{*}$ & $-0.368^{*}$ & -0.248 & 0.066 & $0.415^{* *}$ & $-0.352^{*}$ \\
$R$ & 0.221 & $-0.431^{* *}$ & $-0.529^{* *}$ & $-0.443^{* *}$ & $-0.411^{* *}$ & 0.074 & $0.325^{*}$ & $-0.547^{* *}$ \\
\hline
\end{tabular}

$*$ 表示在 0.05 水平上显著相关, $* *$ 表示在 0.01 水平上显著相关 (双尾检验).

在 Canoco 5.0 中分析表 3 中主要优势属与水质参数之间的相关性. 进行降趋势对应分析 (DCA) 后, 发 现其梯度最大值小于 3 , 即主要优势属与水质参数之间呈线性关系, 故选择 RDA 模型进行相关性分析.

$\mathrm{RDA}$ 排序显示前三轴特征值分别为 $0.3795 、 0.1263 、 0.0531$, 共解释了 $61.80 \%$ 的方差值; 其中环境因子 WT、 $\mathrm{pH} 、 \mathrm{SD}$ 的单独解释量最大, 分别达到 $34.1 \% 、 16.2 \%$ 和 $12.4 \%$, 与特征属关系密切. 其中小环藻、蓝隐藻 属与 $\mathrm{pH}$ 呈正相关, 与 $\mathrm{WT} 、 \mathrm{SD}$ 相关性不显著; 隐藻属与 $\mathrm{SD}$ 呈正相关, 与 $\mathrm{WT} 、 \mathrm{pH}$ 均呈负相关; 衣藻属、四鞭藻 属、浮鞘丝藻属与 WT、 $\mathrm{pH}$ 均呈正相关, 与 SD 呈负相关. 其中衣藻属还与 TSS、Chl.a、COD、TP 均呈正相关.

\section{3 讨论}

\section{1 水质参数变化特征}

月湖属于小型城市浅水湖泊, 相较于太湖、滇池等大型浅水湖泊受风浪摚动的影响较小, 也没有渔业养 殖活动, 与同作为景观湖泊的青山湖、镜湖、西湖等在富营养化污染上有更多共性,均面临湖岸线城市建筑 多、人口密集、城市污染物随地表径流直接进人湖体的问题 ${ }^{[5,7,29]}$. 与青山湖一致, 月湖与富营养化程度较高 


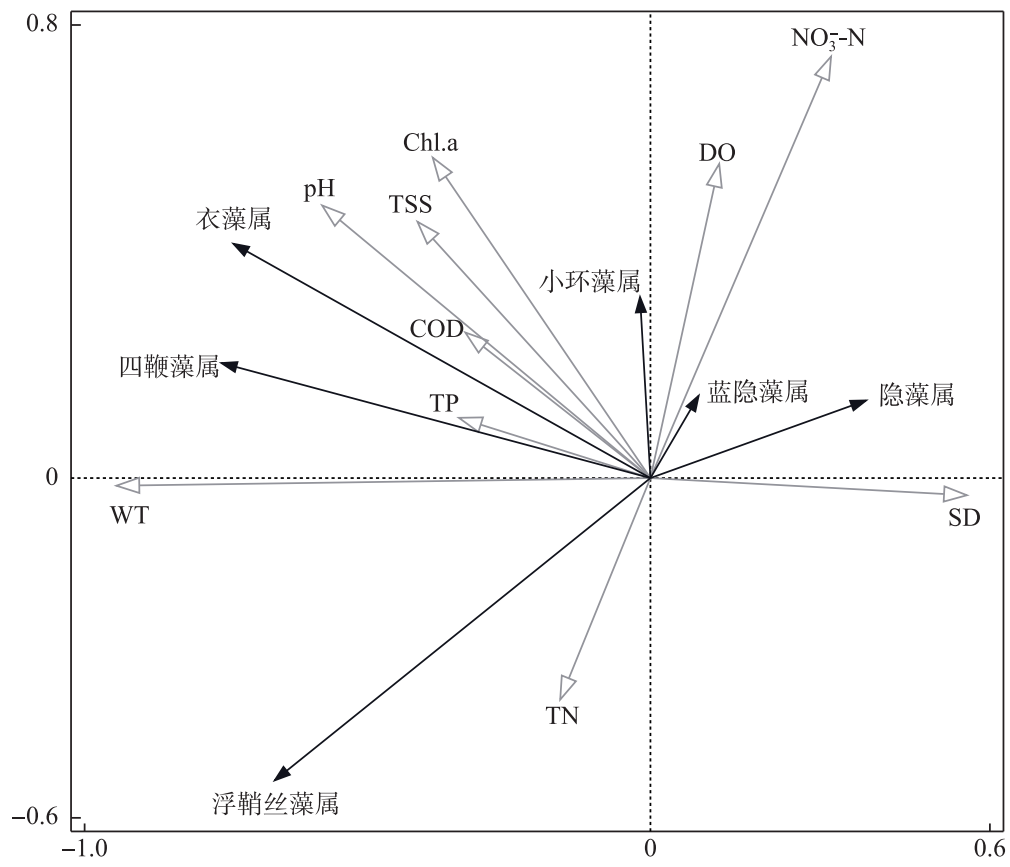

图 4 月湖浮游植物主要特征属与环境因子关系 RDA 排序

Fig.4 RDA ordination biplot of phytoplankton characteristic genus and environmental variables in Moon Lake

的护城河相连、不断有外源污染输人 ${ }^{[5]}$, 由于水体循环不佳造成营养盐累积、水体富营养化. 月湖水质介于 II 劣 V 类, 营养水平介于中一极端富营养之间, 富营养化分级的结果从空间分布上主要表现为北湖高于南 湖、人水口高于出水口、狭窄水面高于开阔水面, 月湖水体较高的营养盐水平构成了水华暴发的物质基础.

根据水华暴发点 S5 的水质参数变化,水华期间水温总体呈上升趋势,水华导致 $\mathrm{pH}$ 、 TSS 浓度上升. 前期 $\mathrm{TN}$ 浓度波动不大, TP 浓度在 3 月 27 日明显下降, 此时 S5 的氮磷比达到 78.09, 当日其他点位氮磷比平均值 也达到 59.26. 据 RDA 分析衣藻属与 $\mathrm{pH} 、 \mathrm{TP}$ 浓度呈显著正相关, 尽管此时水华尚未暴发, 但衣藻属可能已开 始大量增殖并对磷进行消耗利用. 后 TP 浓度持续上升导致氮磷比下降, Xie 等 ${ }^{[30]}$ 在对武汉东湖水华的研究 中发现,水体 $\mathrm{pH}$ 值升高将诱导可溶性磷从沉积物中大量释放,而在富营养化浅水湖泊中沉积物所释放的磷 可作为浮游植物发生水华的重要磷源 ${ }^{\left[{ }^{3} 1\right]}$. 朱咏莉等 ${ }^{[32]}$ 通过室内模拟实验也发现雷氏衣藻的快速增殖与悬 浮会导致 $\mathrm{pH}$ 显著升高、磷素浓度迅速降低, 并直接诱导水一泥体系碱性磷酸酶活性升高. 后期 TP 浓度波动 不大,氮磷比急剧上升主要由于 $\mathrm{TN}$ 浓度上升.

\section{2 浮游植物变化特征与影响因子分析}

从时间上来看月湖浮游植物经历了隐藻门 $\rightarrow$ 硅藻门 $\rightarrow$ 绿藻门 $\rightarrow$ 蓝藻门的演替, 其中绿藻门在丰度和多 样性上均占绝对优势. 隐藻属、针杆藻属、栅藻属、衣藻属等优势属的出现进一步说明月湖的营养状态介于 富营养一重富营养型 ${ }^{[33]}$, 与水质指标评价、Chl. a 浓度分级法的结果基本一致. 水华期间各点衣藻属密度占 比均有提升, 除水华暴发点 S5 外, 与之空间距离相近的 S3、S6 的提升幅度也较为显著, 即水华主要集中于 北湖. 由于水流方向自北向南,南湖的 S1、S2 的衣藻属密度后期亦有小幅上升.

综合浮游植物与环境因子的关系分析发现, 环境因子对月湖浮游植物的数量与结构组成产生影响. Pearson 分析显示藻密度与 TP 浓度呈显著正相关, 月湖浮游植物生长对磷的需求总体高于对氮的需求. 群 落特征指数均与 $\mathrm{pH} 、 \mathrm{Chl}$. a TSS 和 DO 均呈负相关, 随着水华属比例的提升, 水体 $\mathrm{pH}$ 值与 Chl. a 浓度升高, 浮 游植物多样性下降, 各点位间的群落组成差异性减小. 经 RDA 分析, 隐藻属与水温呈负相关, 适宜冷水型环 境; 浮鞘丝藻属与水温、 $\mathrm{TP}$ 浓度、 $\mathrm{pH}$ 均呈正相关, 但与 $\mathrm{TP}$ 浓度、 $\mathrm{pH}$ 相关性明显低于衣藻属; 衣藻属与水温、 
$\mathrm{pH} 、 \mathrm{TP}$ 浓度均呈显著正相关,在水华期间温暖适宜的弱碱性、高营养盐负荷的水体中具有更明显的优势. 由 此衣藻属大量增殖引起总藻密度增加、其他藻类占比下降, 导致浮游植物群落结构单一化. 后期衣藻属增殖 后集聚于水面, 导致水体透明度下降、悬浮物浓度提升, 而衣藻属与透明度呈显著负相关, 由于光合作用受 限大量死亡, 从而造成在溶解氧、营养盐相对充足的情况下, 总藻密度减少、浮游植物群落结构趋于稳定. 洪 尚波等 ${ }^{[34]}$ 亦发现水华暴发会使浮游植物群落变得不稳定,而在水华后期群落稳定性增加.

\section{3 月湖绿藻水华暴发成因分析}

对处于富营养化的水体, 藻类生长不再受到营养盐的限制, 藻类生物量受水文气象条件的影响将超过 营养盐的影响 ${ }^{[19,35]}$. 月湖浮游植物的演替过程与 Sommer 等 ${ }^{[15]}$ 提出的淡水浮游生物季节演替 PEG ( Plankton Ecology Group) 模型有相似之处, 且与主要优势属对水温的适应性对应: 即起初以喜冷水环境的隐藻属占优 势, 后经小环藻属过渡, 逐渐向喜暖水环境的绿藻、蓝藻门演替. 衣藻属与水温呈显著正相关, 水华暴发前水 温上升接近 $10^{\circ} \mathrm{C}$, 为其生长创造良好条件, 致使藻密度急剧增加, 同时较高的水温也决定了月湖此次不会暴 发硅藻、甲藻等狭冷型藻类水华 ${ }^{[14]}$. 绿藻和蓝藻适生温度相近, 引发水华后均会导致 $\mathrm{pH}$ 升高、氮磷比变化, 我国淡水水华暴发多以蓝藻为主, 蓝藻水华也被当作湖泊富营养化的典型特征 ${ }^{[7,36]}$. 然而也有少量研究表 明在超富营养化条件下绿藻将取代蓝藻占优势 ${ }^{[16]}$, 尤其是在 TP 水平较高的浅水、不分层的湖泊中绿藻相 对于蓝藻更具优势 ${ }^{[17]}$.

月湖中的绿藻和蓝藻分别以衣藻属和浮鞘丝藻属为代表. 根据 Reynold ${ }^{[37]}$ 提出的淡水浮游植物 CSR 模 型, 衣藻属为 C-策略型, 具备优于其他类型的营养收集、转化能力, 以高生长率、高死亡率为特点. Jacoby 等 ${ }^{[38]}$ 认为绿藻比蓝藻具有更强的利用高氮磷比条件的优势, 更适应富营养化较高的水环境 ${ }^{[15]}$. 侯秀丽 等 ${ }^{[16]}$ 在研究滇池营养盐对浮游藻类结构影响的过程中亦发现, 靠近城区、营养负荷更高的草海绿藻生物量 高于外海并成为绝对优势澡种. 且在氮磷比较高时, 外海水体中绿藻生物量上升、蓝藻生物量下降. 水华期 间月湖处于中一极端富营养水平, 在营养盐充足的条件下, 前期最大生长速率更高的衣藻属相较于浮鞘丝藻 属更有竞争优势.

随着水华暴发水体浊度增加, 光照成为藻类生长的关键因素. 4 月 24 日 -5 月 3 日的阴天、降雨天气导 致湖面光照不如晴朗时充足, 降雨量增加造成水位波动、原水位处光照进一步减弱, 短期光照不足、降温的 条件致使衣藻属生长受到限制. 浮鞘丝藻属为 $\mathrm{R}$-策略型, 能够适应短光照、利用弱光条件, 其生长率低于 $\mathrm{C}$ 策略型, 对不良生境的适应性高于 $\mathrm{C}$-策略型 ${ }^{[37]}$. 秦伯强等 ${ }^{[36]}$ 认为蓝藻仅需较少的能量就能维持其细胞结构 和功能, 且能够更高效地利用水下的有效光辐射, 在弱光条件下相较于其他藻类具有更高的生长速率, 导致 后期浮鞘丝藻属因其生理优势取代衣藻属. PEG 模型中也指出, 夏末随着深水湖泊混合层深度增加、水下光 照减弱, 早期的小型速生藻类将被耐阴的大型藻类取代, 演替序列中出现的浮游植物类型受湖泊深度与营 养水平影响 ${ }^{[15,39]}$. 月湖作为浅水湖泊尽管没有明显分层现象, 但由于水华暴发、阴雨天气导致水下光照条件 恶化, 其浮游植物变化也呈现从 C-策略型向 R-甚至 S-策略型转变的趋势, 这一变化过程印证了蓝藻水华是 湖泊富营养化过程中某阶段的产物 ${ }^{[16]}$, 而当前月湖的环境条件对衣藻属生长更有利.

此外从水动力条件考虑, 月湖作为城市中心湖泊, 整体水域流速缓慢. 水华期间密度明显提升的衣藻 属、四鞭藻属作为带鞭毛种类游泳能力较强, 更适于生存在流速较小的静水湖泊中 ${ }^{[39]}$. 且衣藻属与 $\mathrm{pH} 、 \mathrm{TP}$ 浓度均呈显著正相关, 月湖水质总体偏弱碱性、营养盐浓度较高, 伴随缓慢的水流速度, 这样的条件极适于 衣藻生长. Ajin 等 ${ }^{[13]}$ 亦发现水体交换不良、伴随高营养负荷易于导致小水面发生水华并引起水域 $\mathrm{pH}$ 升高. 碱性环境进一步促使沉积物中磷的释放, 较高的磷释放率是许多超富营养化浅水湖泊在无机磷浓度较低时 仍以绿藻占优势的原因 ${ }^{[17]}$. 王培丽 ${ }^{[40]}$ 认为磷浓度达到某一水平时, 在较低水流条件下硅藻水华将向绿藻水 华转变. S5 位于湖域小水面, 周围建筑集聚、人类活动密集, 水体流动性相对更差, 加之高于富营养化阀值的 营养盐浓度、适宜的光照和温度条件, 导致此次局部水华的暴发. 针对月湖绿藻水华的防治, 除控制氮磷营 养盐水平尤其是磷营养盐浓度外, 在早春气温回升、光照充足时需通过工程措施增强湖泊水动力特性.

\section{4 结论}

1) 月湖作为城市小型浅水湖泊, 受持续的外源污染输人与水体交换不良等影响, 总体营养程度处于中 
富营养至极端富营养之间, 各点位富营养化程度从高到低依次为 $\mathrm{S} 5>\mathrm{S} 6>\mathrm{S} 3>\mathrm{S} 4>\mathrm{S} 1>\mathrm{S} 2$, 从空间上表现为北 湖高于南湖、人水口高于出水口、水面狭窄区域高于开阔区域.

2) 水华期间共鉴定浮游植物 8 门 61 属 112 种, 以绿藻门和硅藻门为主, 受水温、光照驱动经历了隐藻 门 $\rightarrow$ 硅藻门一绿藻门 $\rightarrow$ 蓝藻门的演替. 3 月 28 日位于北湖的 S5 暴发水华,水华种为雷氏衣藻. 各点位水华 程度与富营养化程度基本对应, 且随衣藻属比例提升, 浮游植物种类数量减少、点位间群落组成差异性减小.

3) 春季气温回升、天气持续晴好, 衣藻属带鞭毛、游泳能力强, 且生长与水温、 $\mathrm{pH}$ 、总磷呈显著正相关, 适 宜在高营养盐负荷、流速缓慢的弱碱性水体中生长. 且衣藻属 C-策略型的生长适应性进一步决定其相对于 其他藻种具备更高的营养收集、转化能力与生长速率,导致此次水华的发生.

致谢: 感谢宁波天河水生态科技股份有限公司施立硕、邓照亮、冯佳慧、何茂贵等在采样工作中给予充分支 持,及中国科学院城市环境研究所城市环境与健康重点实验室王瑞杰在 ArcGIS 作图中提供的帮助.

\section{5 参考文献}

[ 1 ] Yu Y, Peng FL, Sun C et al. Analysis on the characteristics and impact facators of water bloom in the lake. Environmental Monitoring in China, 2017, 33(2) : 88-94. [于洋, 彭福利, 孙聪等. 典型湖泊水华特征及相关影响因素分析. 中国 环境监测, 2017, 33(2) : 88-94.]

[ 2 ] Zhang YH, Li WF, Chen QW. Spatial-temporal variance of the intensity of algal bloom and related environmental and ecological factors in Lake Taihu. Acta Ecologica Sinica, 2016, 36(14): 4337-4345. [张艳会, 李伟峰, 陈求稳. 太湖水华 程度及其生态环境因子的时空分布特征. 生态学报, 2016, 36(14) : 4337-4345.]

[ 3 ] Lv J, Wu HJ, Chen MQ. Effects of nitrogen and phosphorus on phytoplankton composition and biomass in 15 subtropical, urban shallow lakes in Wuhan, China. Limnologica, 2011, 41: 48-56.

[ 4 ] Wen XL, Xi YL, Qian FP et al. Comparative analysis of rotifer community structure infive subtropical shallow lakes in East China: role of physical and chemical conditions. Hydrobiologia, 2011, 661 : 303-316.

[ 5 ] Kuang WM, Zhang M, Zhang JM et al. Comparative limnological study on annual dynamic pattern of nutrients in water column of three suburb lakes adjacent to Lake Poyang. J Lake Sci, 2016, 28(6) : 1293-1305. DOI: 10.18307/2016.0615. [匡武名, 张萌, 张金美等. 鄱阳湖外围湖泊水体营养波动周年特征的比较湖沼学研究. 湖泊科学, 2016, 28(6): 1293-1305.]

[ 6 ] Yang C, Ma JM. Researchprogress of ecological restoration and aquatic plant community construction for urban lake. Journal of Yangtze River Scientific Research Institute, 2014, 31(7): 13-20. [ 杨程, 马剑敏. 城市湖泊生态修复及水生植物 群落构建研究进展. 长江科学院院报, 2014, 31(7): 13-20.]

[ 7 ] Zhu X, Hu MM eds. Control and prevention of cyanobacteria outbreak in freshwater lakes of China. Beijing: China Water and Power Press, 2014: 62-71. [ 朱喜, 胡明明. 中国淡水湖泊蓝藻暴发治理与预防. 北京: 中国水利水电出版社, 2014: 62-71.]

[ 8 ] Chen NW, Zhang YY, Li YF. An integrated analysis of dynamic characteristics of harmful algal bloom in fresh water in China. Ecology and Environmental Sciences, 2010, 19(8): 1994-1998. [ 陈能汪, 章颖瑶, 李延风. 我国淡水藻华长期 变动特征综合分析. 生态环境学报, 2010, 19(8): 1994-1998.]

[ 9 ] Cai QH. Multivariate analysis of planktonic blooms in Lake Donghu, Wuhan. Acta Hydrobiologica Sinica, 1990, 14(1): 22-31. [蔡庆华. 武汉东湖浮游植物水华的多元分析. 水生生物学报, 1990, 14(1): 22-31.]

[10] Affan MA, Touliabah HE, Al-harbi SM et al. Influence of environmental parameters on toxic cyanobacterial bloom occurrence in a Lake of Bangladesh. Rendiconti Lincei, 2016, 27: 473-481.

[11] Bazhenova OP, Krentz OO. Phytoplankton as an indicator of ecological state of the Saltaim-Tenis Lake System (Omsk Region). Contemporary Problems of Ecology, 2018, 11(2): 168-178.

[12] Suikkanen S, Laamanen M, Huttunen M. Long-term changes in summer phytoplankton communities of the open northern Baltic Sea. Estuarine, Coastal and Shelf Science, 2007, 71: 580-592.

[13] Am A, Silvester R, Alexander D et al. Characterization of blooming algae and bloom-associated changes in the water quality parameters of traditional pokkali cum prawnfields along the South West coast of India. Environmental Monitoring and Assessment, 2016, 188: 145.

[14] Huang YN, Ji DB, Long LH et al. The variance analysis of characteristics and blooms of the typical tributaries of the Three 
Gorges Reservoir in spring. Resourse and Environment in the Yangtze Basin, 2017, 26(3) : 461-470. [黄亚男, 纪道斌, 龙良红等. 三峡库区典型支流春季特征及其水华优势种差异分析. 长江流域资源与环境, 2017, 26(3) : 461-470.]

[15] Sommer U, Gliwicz M, Lampert W et al. The PEG-model of seasonal succession of planktonic events in fresh waters. Achieves of Hydorbiology, 1986, 106: 433-471.

[16] Hou XL, Yuan CG, Li XP et al. Effect of nitrogen and phosphorus concentrations on the planktonic algae dynamics in Dianchi Lake. Journal of Hydroecology, 2018, 39(1) : 16-22. [侯秀丽, 苑春刚, 李学平等. 滇池氮磷浓度变化对蓝、 绿、硅藻年际变化的影响. 水生态学杂志, 2018, 39(1): 16-22.]

[17] Jensen JP, Jeppesen E, Olrik K et al. Impact of nutrients and physical factors on the shift from cyanobacterial to chlorophyte dominance in shallow Danish Lakes. Canadian Journal of Fisheries and Aquatic Sciences, 1994, 51( 8) : 1692-1699.

[18] Wu XH, Yin DC, Li C et al. Analysis of factors influencing diatom blooms in the middle and lower Hanjiang River. Journal of Hydroecology, 2017, 38(6) : 19-26. [ 吴兴华, 殷大聪, 李朋中等. 2015-2016 年汉江中下游硅藻水华发生成因 分析. 水生态学杂志, 2017, 38(6): 19-26.]

[19] Zhu GW, Jin YW, Ren J et al. Characteristics of diatom blooms in a reservoir-water supply area and the countermeasures in Taihu Basin, China. J Lake Sci, 2016, 28(1) : 9-21. DOI: 10.18307/2016.0102. [ 朱广伟, 金颖薇, 任杰等. 太湖 流域水库型水源地硅藻水华发生特征及对策分析. 湖泊科学, 2016, 28(1):9-21.]

[20] Hu ZJ, Mo DM, Zhou XY et al. Spatial and seasonal distribution of phytoplankton in Qiandao Lake and relationship with environmental factors. Journal of Hydroecology, 2017, 38(5): 46-54. [胡忠军, 莫丹玫, 周小玉等. 千岛湖浮游植物 群落结构时空分布及其与环境因子的关系. 水生态学杂志, 2017, 38(5) : 46-54.]

[21] Chen YW, Chen KN, Hu YH. Disscussion on possible error for phytoplankton chlorophyll-a concentration analysis using hot-ethanol extraction method. J Lake Sci, 2006, 18(5) : 550-552. DOI: 10.18307/2016.0526. [陈宇炜, 陈开宁, 胡耀 辉. 浮游植物叶绿素 a 测定的“热乙醇法” 及其测定误差的探讨. 湖泊科学, 2006, 18(5): 550-552.]

[22] Hu HJ, Wei YX eds. Freshwater algae in China: System, classification and ecology. Beijing: Scienc Press, 2006. [胡鸿 钧, 魏印心. 中国淡水藻类——系统、分类及生态. 北京: 科学出版社, 2006.]

[23] Weng JZ, Xu HS eds. Atlas of common freshwater phytoplankton in China. Shanghai: Shanghai Science and Technology Press, 2010. [翁建中, 徐恒省. 中国常见淡水浮游藻类图谱. 上海: 上海科学技术出版社, 2010.]

[24] Ministry of Water Resources, Yangtze River Basin Water Environment Monitoring Center eds. Atlas of algae species in inland waters of China. Wuhan: Changjiang Press, 2012. [水利部水文局, 长江流域水环境监测中心. 中国内陆水域常 见藻类图谱. 武汉: 长江出版社, 2012.]

[25] Zhang R, Su J, Huo SL et al. The tropic status evaluation and development of nutrient water quality standards for Fuxian Lake. Journal of Environmental Engineering Technology, 2012, 2(3): 218-222. [张芯, 苏婧, 霍守亮等. 抚仙湖营养 状态评价及营养物水质标准制定. 环境工程技术学报, 2012, 2(3) : 218-222.]

[26] Gao YJ, Cao Y, Zhao Z et al. Study on the eutrophication control standard for eastern lake basing on the chlorophyll-a classfication. Environmental Science and Technology, 2011, 34(12) : 218-220. [高阳俊, 曹勇, 赵振等. 基于叶绿素 a 分级的东部湖区富营养化标准研究. 环境科学与技术, 2011, 34(12): 218-220.]

[27] Belaoussoff S, Kevan PG, Murphy S et al. Assessing tillage disturbance on assemblages of ground beetles (Coleoptera: Carabidae) by using a range of ecological indices. Biodiversity and Conservation, 2003, 12 : 851-882.

[28] Lai JS. Canoco 5: a new version of an ecological multivariate data ordination program. Biodiversity Science, 2013, 21(6): 765-768. [赖江山. 生态学多元数据排序分析软件 Canoco 5 介绍. 生物多样性, 2013, 21(6) : 765-768.]

[29] Wen XL, Feng RN, Zhang G et al. Temporal variations of chlorophyll-a concentration and their relationships with abiotic and biotic factors in two small shallow lakes. J Lake Sci, 2017, 29(6) : 1421-1432. DOI: 10.18307/2017.0614. [温新 利, 冯若楠, 张根等. 两小型浅水湖泊水体叶绿素 a 浓度的季节变化及与理化因子和生物因子的关系. 湖泊科学, 2017, 29(6) : 1421-1432.]

[30] Xie LQ, Xie P, Tang HJ. Enhancement of dissolved phosphorus release from sediment to lake water by Microcystis blooms-An enclosure experiment in a hyper-eutrophic, subtropical Chinese lake. Environmental Pollution, 2003, 122 : 391-399.

[31] Jacoby JM, Lynch DD, Welch EB et al. Internal phosphorus loading in a shallow eutrophic lake. Water Research, 1982, 16: 911-919.

[32] Zhu YL, Wu Q, Xu S et al. Effects of Chlamydomonas reinhardtii proliferating, blooming and decaying on dynamics of 
phosphorus in water column and sediments. Jounal of Nanjing Forestry University: Natrual Sciences Edition, 2014, 38(6) : 60-64. [ 朱咏莉, 吴清, 徐莎等. 衣藻增殖、悬浮与沉降过程对水一泥界面磷素动态的影响. 南京林业大学学报: 自 然科学版, 2014, 38(6): 60-64.]

[33] Jin XC, Tu QY eds. Investigation specification for lake eutrophication. Beijing: China Environmental Science Press, 1990. [金相灿，屠清瑛. 湖泊富营养化调查规范. 北京: 中国环境科学出版社, 1990.]

[34] Hong SB, Wu GY, Wan D et al. Distribution of algae and its influencing factors in Daning River in Three Gorges Resevoir during period of spring algal bloom. Water Resource Protection, 2012, 28(1) : 80-84. [洪尚波, 吴光应, 万丹等. 三峡 水库大宁河春季水华藻类分布及影响因子. 水资源保护, 2012, 28(1) : 80-84.]

[35] Zhu GW, Qin BQ, Zhang YL et al. Variation and driving factors of nutrients and chlorophyll-a concentrations in northern region of Lake Taihu, China. J Lake Sci, 2018, 30(2) : 279-295. DOI: 10.18307/2018.0201. [ 朱广伟, 秦伯强, 张运 林等. 2005-2017 年北部太湖水体叶绿素 a 和营养盐变化及影响因素. 湖泊科学, 2018, 30(2) : 279-295.]

[36] Qin BQ, Xu H, Dong BL eds. The principle and practice of eutrophic lake restoration and magagement. Beijing: Higher Education Press, 2011: 166-187. [秦伯强, 许海, 董百丽. 富营养化湖泊治理的理论与实践. 北京: 高等教育出版 社, 2011: 166-187.]

[37] Reynolds CS ed. The ecology of phytoplankton. New York: Cambridge University Press, 2006: 208-238.

[38] Jacoby JM, Collier DC, Welch EB et al. Environmental factors associated with a toxic bloom of Microcystis aeruginosa. Canadian Journal of Fisheries and Aquatic Sciences, 2000, 57(1): 231-240.

[39] Scheffer M ed. Ecology of shallow lakes. Netherlands: Kluwer Academic Publishers, 1998: 85-117.

[40] Wang PL ed. Studies on the formation mechanism of diatom blooms in Hanjiang River from hydrodynamics and nutrition. Wuhan: Huazhong Agricultural University, 2010. [王培丽. 从水动力和营养角度探讨汉江硅藻水华发生机制的研究. 武汉: 华中农业大学, 2010.] 